\title{
La toma del Palacio de Justicia en la memoria colectiva
}

\author{
The occupation of the Palace of Justice in the collective memory
}

jhcaldana@yahoo.com

nzumanaa@unal.edu.co

Fue un momento de pánico. Un momento violento, porque ver uno que toda esa gente se había metido, que había toda esa gente ahi encerrada, con ese peligro. ¡Todo lo que sucedió fue aterrador! No solo la matanza y la masacre, sino también los desaparecidos. Ahí hubo de todo. Eso es terrible.

Alicia

Trabajadora social

Este artículo presenta parte de los resultados de la investigación escolar sobre la memoria colectiva en torno a los hechos del Palacio de Justicia, sucedidos durante los días 6 y 7 de noviembre de 1985. Está acompañado del testimonio de un soldado del Batallón Guardia Presidencial que participó directamente de los hechos; de esta manera se hace énfasis en la metodología utilizada por la historia oral.

Palacio de Justicia, memoria colectiva, historia oral.
This article presents partial results of a research conducted in a school setting, on the collective memory about the facts of the Palace of Justice. Those events took place on the 6th and 7th of November, 1985. This report is accompanied by the testimony of a soldier from the Batallón Guardia Presidencial who participated directly in the events. In this way emphasis is placed on the methodology used by oral history.

Palace of Justice, collective memory, oral history.

* Geógrafo, Universidad Nacional de Colombia; licenciado en Ciencias Sociales, Universidad Pedagógica Nacional; docente tiempo completo, Departamento de Ciencias Sociales, Universidad Pedagógica Nacional.

** Estudiante de Sociología, Universidad Nacional de Colombia y de Literatura, Pontificia Universidad Javeriana. 


\section{Presentación}

\section{La incursión de la historia oral en la escue- la colombiana durante los últimos años ha} sido fecunda desde las propuestas teóricas, metodológicas e investigativas que se hallan en diferentes publicaciones sobre el tema'. Los trabajos han estado orientados a presentar las indagaciones realizadas con estudiantes de educación básica y media, especialmente en temas que comprenden las historias de vida y las historias barriales elaboradas en distintos grados de formación escolar ${ }^{2}$. Estos han permitido, en doble dimensión, una mejor comprensión de los conceptos fundamentales de la disciplina histórica, como son los de tiempo histórico, tiempo cronológico, fuentes primarias, etc., y por el otro, la reflexión pedagógica y didáctica en términos de la enseñanza de la historia, al permitir un aprendizaje significativo por el contacto directo de los estudiantes con los problemas históricos del tiempo presente, la posibilidad de un papel activo frente a la historia, en lugar de uno pasivo, actitud de la enseñanza convencional en la que se limita al libro de texto o a la exposición oral del profesor. En la propuesta de la historia oral, la reconstrucción del pasado cuenta con la participación directa de los estudiantes, así estos tienen la posibilidad de reconstruir el pasado recurriendo a las fuentes primarias, incluyendo las propuestas teóricas, metodológicas y conceptuales que brinda esta forma de conocimiento social.

Considerando las ideas anteriores, la investigación denominada "La memoria colectiva y la toma del Palacio de Justicia" se adelantó durante los años 2003 a 2005 con algunos estudiantes de los grados décimo y undécimo del Liceo Juan Ramón Jiménez en el espacio denominado "Proyecto académico" con la propuesta general "Aprendiendo historia haciendo historia" que permitió ampliar la perspectiva de los estudios escolares utilizando la metodología de la historia oral, que hasta el momento había desarrollado las temáticas de las

\footnotetext{
1 A partir del libro de Sitton, Thad y Mehaffy, George. 1989. Historia oral: una guía para profesores (y otras personas). México: Fondo de Cultura Económica, han sido estructuradas propuestas metodológicas para la enseñanza de la historia en Colombia. Ver también Vega, Renán. 1999. Historia: conocimiento y enseñanza. Bogotá: Ediciones Antropos.

2 Por ejemplo, los resultados presentados en los libros de Vega, Renán y Castaño, Ricardo (compiladores). 1999. Déjenos hablar. Bogotá: Universidad Pedagógica Nacional - Instituto de Investigación Educativa y Desarrollo Pedagógico, y Castro, Fabio. 2004. Historia oral: historias de vida e historias barriales. Bogotá: IED Manuelita Sáenz, Colectivo de Historia Oral, Aspectos Siglo XXI.
}

historias de vida o barriales, y que se extendió en esta oportunidad para reconstruir un hecho de nuestra historia política relacionado dentro de la historiografía con la historia de la violencia, en el sentido en que la violencia aparece como una extensión de la política ejercida por otros medios y que supera los modos convencionales de ejercerla en los ámbitos del Estado, el sistema y los partidos políticos (Ortiz, 1995: 371).

Para nosotros significó ampliar el uso de la historia oral a campos que hasta el momento, teniendo en cuenta las publicaciones citadas, no se habían explorado en la escuela, y que permanecían vivos dentro de la memoria colectiva de la mayoría de la población, pero que los estudiantes no tenían como referente histórico -incluyendo al profesor que para la fecha de la toma del Palacio de Justicia tenía seis años-, que por los mecanismos reguladores de la memoria social habían quedado disueltos, sin mayor información, a pesar de que sus padres, abuelos o personas cercanas pudieran recordarlo. Para los estudiantes aparecía una historia del siglo XX que no superaba los hechos de la Violencia partidista derivados, entre otras causas, del asesinato de Jorge Eliécer Gaitán el 9 de abril de 1948, de modo que quedaba olvidado medio siglo en la estructura curricular. Fue, entonces, la posibilidad de explorar significativamente los hechos históricos recientes a partir del relato, del testimonio, que los hizo mucho más cercanos y vivenciales.

En ese sentido, el desarrollo de la investigación se abordó desde una propuesta didáctica que partió de la disciplina con la tesis central de aprender historia haciendo historia. Para ello recurrimos a las fuentes teóricas y metodológicas de la historia oral, teniendo en cuenta las diversas etapas de la investigación social (elaboración del proyecto, recolección de la información, análisis, redacción y socialización de los resultados). El proceso de formulación dio como resultado reconstruir los hechos de la toma del Palacio de Justicia a partir de la memoria colectiva, se hizo una revisión sobre las categorías que permitieron orientar el proyecto de investigación. Igualmente, se realizaron distintos talleres relacionados con elaboración de entrevistas, análisis de datos y redacción final del documento, unido a un trabajo de socialización que superó el espacio físico de la escuela y que se trasladó a diversos escenarios. A continuación presentamos los fundamentos teóricos, metodológicos, conceptuales, resultados y conclusiones de la investigación. Los resultados los hemos querido acompañar de un testimonio que permita observar con mayor riqueza el proceso investigativo. 


\section{La historia oral}

Frente a la historia indiferente, entorpecida de abstracciones y de estadísticas, que le teme a lo local, a las anécdotas y a los héroes, se alza la historia viva que muestra a las tragedias humanas girando en torno de cosas concretas, de gallinas y de cerdos, de fotografías y de sillas vacías.

William Ospina

En lo concerniente al marco teórico, metodológico y conceptual de la investigación, esta giró en torno al rescate de la memoria colectiva a través de la historia oral de los hechos de la toma del Palacio de Justicia, que ocurrieron durante los días 6 y 7 de noviembre de 1985. A partir de la revisión conceptual emergieron una cantidad importante de características que fueron aumentando y contrastándose con la práctica investigativa. Inicialmente se tuvo como referencia el libro Historia oral: una guía para profesores (y otras personas), de Sitton y Mehaffy, en el que los autores parten por definir la historia oral como un procedimiento válido de investigación social dentro del trabajo del historiador, y que se convierte en una alternativa a las tendencias historiográficas hasta ahora creadas y dominantes. A partir de allí, caracterizamos y confrontamos en la práctica misma la propuesta de la historia oral, desde su potencial en el campo disciplinar en general, y su valor pedagógico en particular.

La historia oral ha sido considerada como tradición oral, transmitida a partir de la narración de cuentos, mitos, bromas, anécdotas, versos, coplas, etc., que han venido desapareciendo dentro de las distintas formas de construcción del conocimiento popular, donde se comienzan a privilegiar otras maneras de comprender el pasado. En ese sentido, el trabajo a partir de fuentes orales busca rescatar estas perspectivas, señalando como legítimas las diversas formas de narrar el pasado, especialmente para los grupos subalternos que se alejan de la historia oficial y escrita.

En principio, resaltamos que la historia oral está formada por las memorias y recuerdos de la gente viva sobre su pasado, por tanto, es una historia en la que emergen emociones y sentimientos, que se manifiestan en el momento de dar el testimonio; del mismo modo, existe un límite temporal para la reconstrucción del pasado, que va hasta la existencia física de las personas.
Además, los proyectos de historia oral se convierten en una profunda innovación pedagógica debido a que son elaboraciones realizadas por los mismos profesores en su práctica cotidiana. En la actualidad son muchos los profesores de ciencias sociales que realizan sus actividades académicas desde las fuentes orales y han ido incorporando los elementos de la historia oral, robusteciendo el currículo escolar con iniciativas que parten del contexto escolar y las realidades sociales de los estudiantes. Son muchos los que comienzan acudiendo a la tradición oral: cuentos, mitos, leyendas o el testimonio de adultos para reconstruir un proceso determinado en sus clases, muchas veces de manera intuitiva y luego continúan dando forma a sus propuestas didácticas. La importancia inicial radica en que es una elaboración que parte desde los mismos profesores en contextos que son reales.

Así mismo, los proyectos de historia oral implican dos elementos que resultan cruciales. El primero, que los estudiantes tienen una actitud activa frente al conocimiento, son ellos mismos los que reconstruyen el pasado ya que hacen parte de la misma investigación, en el proceso de diseño, recolección de la información, análisis y presentación de los resultados; segundo, los proyectos de historia oral se hacen, en parte, por fuera del aula, permitiendo que trascienda los límites físicos de la escuela y la integración e interacción con otros contextos, ya sea con sus padres, la comunidad en la que habitan o con otros grupos sociales con los cuales difícilmente tendrían contacto, con quienes pueden intercambiar diversas formas de conocimiento de lo social.

También, pueden llenar los vacíos dejados por la historia tradicional sobre el conocimiento local, donde son ellos los mismos actores, los protagonistas o sabedores de los hechos, pero a los que generalmente no se tiene en cuenta por estar dominados, supuestamente, por estructuras sociales más significativas. La metodología permite dar voz a los excluidos de la historiografía dominante y poder reconocerlos como sujetos hacedores de historia desde lo local, en la que se reconocen como sujetos sociales dinámicos y transformadores. De la misma manera, la historia oral permite fortalecer los lazos con los procesos locales al permitir un contacto más cercano con situaciones sociales que, generalmente, vinculan problemáticas afines a los intereses de los estudiantes, quienes viven, perciben o proceden frente a ellas de distintas maneras y que pueden ser reconocidas y reconstruidas desde la historia oral, permitiendo un conocimiento más profundo 
de la escala por donde se mueven en la vida cotidiana, y logran reconocerse como parte del entorno y fortalecen su identidad.

Es por eso que desde allí se logra uno de los objetivos más relevantes del ejercicio histórico: establecer una correspondencia profunda entre las dinámicas de los propios individuos (experiencias vitales) con la comunidad en que viven y el mundo más amplio que los rodea. Es la posibilidad de reconocerse como parte de los procesos sociales e históricos en distintas escalas, que todas las esferas tienen una relación con las otras, por tanto, lo que hacemos mantiene un vínculo con lo que sucede en lo local, regional, nacional y global.

A su vez, la historia oral por estar elaborada con testimonios de personas está sometida a toda la vaguedad y fragilidad de la mente humana, en lo que se refiere al recuento de los hechos históricos o a la subjetividad que resulta en el testimonio. Por tanto, no se puede considerar como objetiva; por el contrario, es una fuerte crítica a las tendencias de investigación social que tienen ese propósito, a las que recurren al documento escrito, aquellas que buscan la "verdad". Es, por demás, una oportunidad de ver las representaciones simbólicas sobre la realidad la que interesa observar a partir del testimonio. La historia oral está altamente relacionada con la recuperación de la memoria colectiva de las clases populares, sus símbolos y representaciones que las constituyen como grupo social.

Además, existe un elemento afectivo con el pasado y su reconstrucción. En el momento en que se entró en contacto con los hechos del Palacio de Justicia, las estudiantes comenzaron a revalorizarlo, resignificarlo, llenarlo de sentido, les estaba brindando respuestas a preguntas que iban surgiendo durante la investigación y por tanto había que continuar el trabajo propuesto. Son diversas las emociones y la subjetividad que suscita y permite una mayor compenetración por los caminos azarosos de la investigación, que superó, por la iniciativa de las estudiantes, el escenario del colegio y continuó en el ámbito universitario, gracias al compromiso adquirido con los actores y la comprensión de los hechos a partir de las representaciones del presente. También nos permite afirmar que fortalece el trabajo autónomo de los estudiantes porque, además, son proyectos que deben realizarse en espacios distintos al aula de clase, donde no solo debe lograrse la responsabilidad adquirida con los objetivos de los proyectos, sino porque hay un elemento emotivo en su cumplimiento.
Adicionalmente, el compromiso con el proyecto se logró gracias a que fue real y produjo resultados tangibles, por ser las mismas estudiantes quienes se acercaron al problema y porque tuvieron un contacto directo con el hecho histórico. Al final del proceso, entregaron las correspondientes crónicas que se convierten en un material asequible a todos, producto de un trabajo continuo y que resulta bastante significativo al momento de socializar los informes finales con los distintos miembros de la comunidad escolar. Las estudiantes revalorizan la historia, en este caso, por hacer parte de su reconstrucción y comprender la complejidad e importancia de la disciplina histórica como forma válida para el conocimiento de la realidad social.

De la misma manera, permite desarrollar una serie de habilidades que son difíciles de adquirir a través de la construcción de conocimiento tradicional en la escuela, relacionado con el desarrollo de la investigación social misma, en el proceso de elaboración del proyecto, el diseño de las preguntas apropiadas, en planear las estrategias metodológicas para obtener la información y trabajar en equipo; en el momento de conseguir los testimonios: hallar empatía con el entrevistado, tener una idea general sobre la conversación sin perder el hilo del diálogo; en el análisis, hacer un tratamiento adecuado de los datos: transcribiendo, ordenando, organizando y jerarquizando la información; y en la redacción final del documento, componer el texto apoyándose en otras asignaturas, por ejemplo, la clase de español que facilita la redacción, teniendo en cuenta la ortografía y la gramática; y socializar la experiencia utilizando distintos recursos audiovisuales. En este caso, no de manera retórica, permite el trabajo interdisciplinario con las materias de español, lenguas o informática para la sistematización, análisis de los datos y presentación de los resultados finales.

\section{La memoria colectiva y los marcos sociales de la memorización}

La experiencia y la memoria colectivas rebosan en Colombia de hechos violentos, vividos o percibidos, pero incongruentemente establecidos como una normalidad, mientras que un proyecto de paz, basado en la igualdad y la posibilidad de una vida digna para la gran mayoría de la población ha estado completamente ausente.

Efrén Mesa 


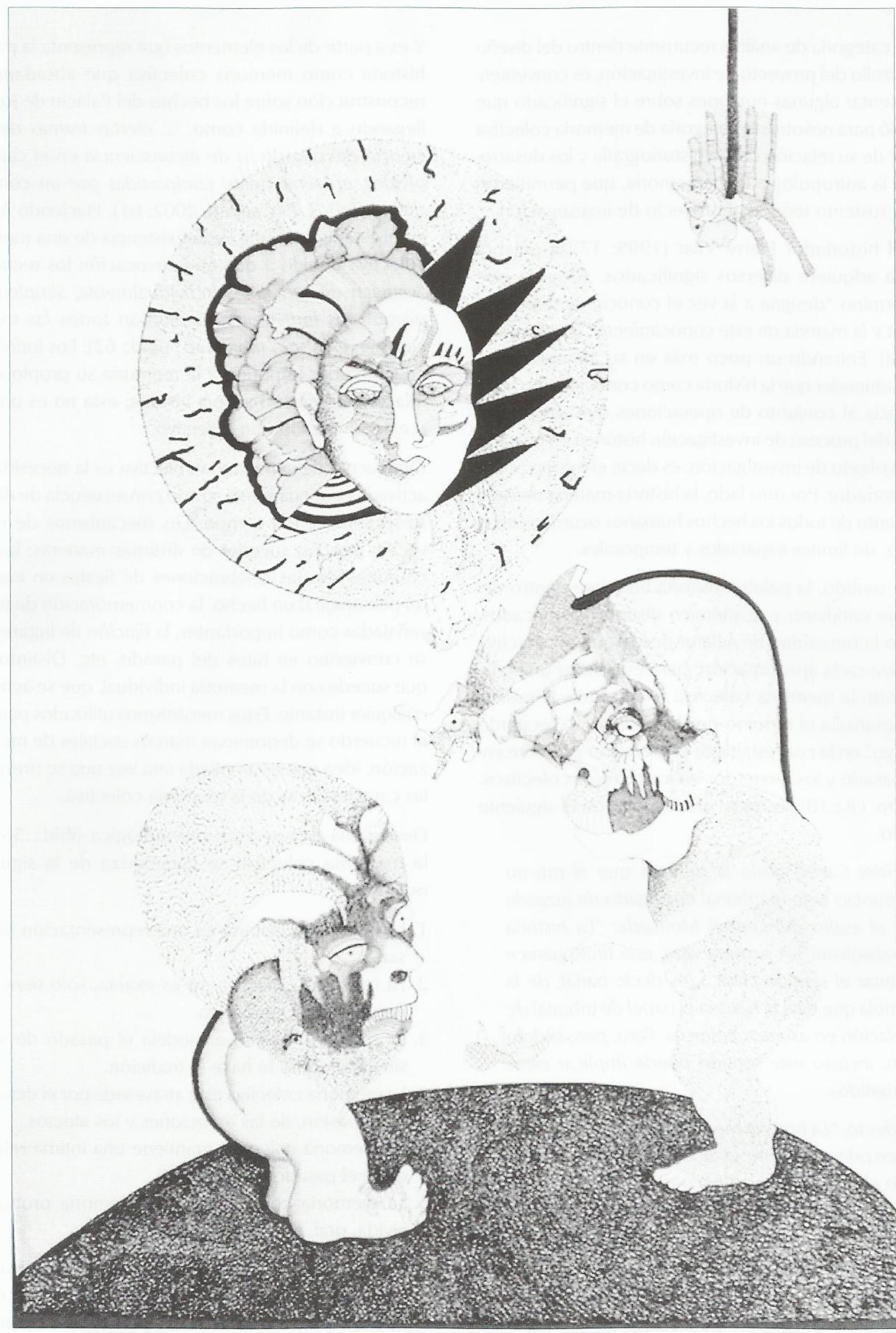


Como categoría de análisis recurrente dentro del diseño y desarrollo del proyecto de investigación, es conveniente presentar algunas nociones sobre el significado que adquirió para nosotros la categoría de memoria colectiva a partir de su relación con la historiografía y los desarrollos de la antropología de la memoria, que permitieron dar un sustento teórico al proyecto de investigación.

Para el historiador Pierre Vilar (1999: 17) la palabra historia adquiere diversos significados. Asegura que este término "designa a la vez el conocimiento de una materia y la materia de este conocimiento" (cursivas del original). Entrando un poco más en su afirmación, se puede entender que la historia como conocimiento hace referencia al conjunto de operaciones que se realizan dentro del proceso de investigación histórica en relación con un objeto de investigación, es decir, el mismo oficio del historiador. Por otro lado, la historia-materia designa el conjunto de todos los hechos humanos ocurridos en el pasado, sin límites espaciales y temporales.

En ese sentido, la palabra historia adquiere dentro del lenguaje cotidiano y académico distintos significados, por eso la necesidad de aclarar desde qué perspectiva se realiza cada aproximación ${ }^{3}$ para establecer una relación entre la memoria colectiva y la historia. El mismo Vilar desarrolla el término de "historia como recuerdo colectivo" en la cual establece esa relación existente entre el pasado y los recuerdos de los diversos colectivos. Vilar (óp. cit.: 18) ilustra su afirmación con el siguiente ejemplo:

... Fidel Castro tituló la defensa que él mismo pronunció ante el tribunal encargado de juzgarle por el asalto del cuartel Moncada: "La historia me absolverá". A primera vista, este título parece adoptar el sentido clásico, es decir, banal, de la fórmula que da a la historia el papel de tribunal de apelación en asuntos políticos. Pero, pensándolo bien, incluso este sentido puede implicar otros contenidos.

En efecto, "La historia me absolverá" puede significar en primer término: el tribunal va a condenarme, pero el recuerdo colectivo que se conservará del hecho acabará siéndome favorable. Y esta noción de "recuerdo colectivo" es otro aspecto del término "historia".

3 Un análisis sobre este tema lo realiza Torres, Alfonso. 1993. Iniciación a la investigación histórica. Bogotá: Universidad Santo Tomás, pp. 21-22.
Y es a partir de los elementos que representa la palabra historia como memoria colectiva que abordamos la reconstrucción sobre los hechos del Palacio de Justicia, llegando a definirla como "... ciertas formas de conciencia del pasado (o de inconsciencia en el caso del olvido), aparentemente compartidas por un conjunto de individuos..." (Candau, 2002: 61). Haciendo énfasis en el estado aparente de la existencia de una memoria colectiva debido a que en la evocación los recuerdos "estarían diferenciados individualmente, simplemente porque los individuos no piensan todos las mismas cosas en el mismo momento" (ibíd.: 62). Los individuos en su interior imponen a la memoria su propio estilo, relacionado con su propia historia; esta no es unívoca o extensiva a todo un colectivo.

Otra faceta de la memoria colectiva es la necesidad de activarla continuamente, como consecuencia de diluirse su recuerdo en el tiempo. Los mecanismos de reactivación pueden suceder de distintas maneras; las más comunes son las celebraciones de fiestas en honor a un personaje o un hecho, la conmemoración de fechas señaladas como importantes, la fijación de lugares que se convierten en hitos del pasado, etc. Distinto a lo que sucede con la memoria individual, que se activa en cualquier instante. Estos mecanismos utilizados para fijar el recuerdo se denominan marcos sociales de memorización, idea que es ampliada una vez que se presentan las características de la memoria colectiva.

Desde una perspectiva antropológica (ibíd.: 56-86), la memoria colectiva se caracteriza de la siguiente manera:

1. La memoria colectiva es una representación del pasado.

2. La memoria colectiva no es exacta, solo tiene apariencia de ser verdadera.

3. La memoria colectiva modela el pasado de forma similar a como lo hace la tradición.

4. La memoria colectiva está atravesada por el desorden de la pasión, de las emociones y los afectos.

5. La memoria colectiva mantiene una íntima relación entre el pasado y el presente.

6. La memoria colectiva es una memoria producida, vivida, oral, normativa, corta y plural.

Lo anterior nos permite señalar que esta investigación, basada en la memoria individual y colectiva, recogida a partir del testimonio oral, no pretende mostrar con precisión los hechos ocurridos antes, durante y des- 
pués de la toma del Palacio de Justicia. Por el contrario, busca revelar las ambigüedades, pasiones, emociones y afectos que surgen al recordar los hechos del Palacio de Justicia y la forma como esos recuerdos estructuran las representaciones en el presente.

Por otro lado, los marcos sociales de la memorización permiten que los miembros pertenecientes a la sociedad fijen sus recuerdos. Estos marcos integran los antiguos recuerdos dentro de los nuevos que están en construcción. "Cuando estos marcos se destruyen, se rompen, se dislocan o, simplemente, se modifican, los modos de memorización de una determinada sociedad y de sus miembros se transforman para adaptarse a los nuevos marcos sociales que habrán de instaurarse" (ibíd.: 66).

Es importante señalar que las actividades conmemorativas, oficiales o no, buscan, por su ausencia, motivar el olvido, o, a través de la presencia, la afirmación de la memoria. Sin embargo, en estos procesos conmemorativos no existe necesariamente una crítica hacia el pasado. Así mismo, la memoria toma elementos de larga duración para establecer relaciones con el presente o legitimar sus acciones.

\section{Desarrollo metodológico}

La implementación del proyecto se llevó a cabo durante tres años (2003, 2004 y 2005); en lo concerniente al desarrollo metodológico, la investigación tuvo varios momentos; como parte del proceso de formulación, se realizó una presentación general de la propuesta a los estudiantes de los grados décimo y undécimo para que ellos seleccionaran una, entre las ofrecidas por distintas materias, y la inscribieran como parte de su formación escolar en el espacio denominado "proyecto académico".

En un segundo momento, dentro del marco teórico, conceptual e investigativo, se hizo una aproximación a la historia como disciplina, a la historia oral y un énfasis particular en la investigación cualitativa, prestando especial atención al proceso de recolección de la información (obtención de los testimonios orales a partir de entrevistas abiertas, individuales o grupales a profundidad con un estilo narrativo), el manejo de los datos (transcripción, organización, jerarquización y categorización) y la presentación de los resultados a través de crónicas. Para lograr un mejor acercamiento al tema de la investigación cualitativa, se diseñaron varios talleres de elaboración y aplicación de entrevistas en el mismo colegio para conseguir una mayor familiaridad con la herramienta, resultados que se discutían y retroalimentaban en el espacio del proyecto académico.

En un tercer momento se hizo una revisión de las investigaciones sobre el tema (Vélez y Atehortúa, 1993), en su mayoría publicaciones periodísticas, así como una exploración de los antecedentes históricos de la toma a través del libro de Laura Restrepo, Historia de una traición (1986), que nos permitió un contexto general sobre el M-19, las tensiones políticas con el Estado y las Fuerzas Militares, delimitando con mayor precisión el curso que tomaría la investigación. Esta revisión permitió que las estudiantes elaboraran una propuesta dentro del tema general, siguiendo el criterio básico de recuperar la memoria colectiva sobre los hechos del Palacio de Justicia.

Por ello, analíticamente la investigación se dividió en cuatro temáticas a partir de las cuales se reunieron los testimonios: soldados, M-19 y la "gente del común", en la segunda etapa de la investigación surgió el tema de los desaparecidos de la cafetería. Las estudiantes diseñaron sus proyectos en cada uno de los temas que seleccionaron a partir del enfoque de la historia oral.

En un cuarto momento, las estudiantes iniciaron sus investigaciones, concentrándose en cada uno de los actores sociales agrupados en las categorías analíticas diseñadas. Desde el enfoque cualitativo crearon las pautas generales de las entrevistas buscando siempre profundizar en las representaciones que tenía cada uno de los entrevistados sobre los hechos de la toma del Palacio de Justicia. El primer grupo, de dos estudiantes, tuvo la oportunidad de entrevistar a un par de soldados del Batallón Guardia Presidencial, uno de los cuales participó de la retoma del Palacio por parte de las Fuerzas Militares (ver parte de la crónica en este artículo) y el otro, ranchero de esa unidad militar. El segundo grupo adelantó dos entrevistas: la primera, a un grupo de mujeres reinsertadas del M-19 a través de la metodología de entrevista grupal, complementada con un último encuentro individual; la otra entrevista se realizó a Vera Grave, líder del M-19. El tercer grupo desarrolló una serie de entrevistas a personas que, sin tener una relación directa con los hechos, permitieron reconstruir y articular, a partir de otra dimensión -desde la "gente del común", como se denominó- la vida cotidiana de la mayoría de la población, quienes percibieron de manera diversa los hechos, lo que permitió observar 
las representaciones simbólicas construidas a partir de la prensa, la radio, las imágenes de televisión y el diálogo con otras personas. Un cuarto grupo, a partir de las primeras indagaciones con los entrevistados que hacían un énfasis particular sobre los desaparecidos, quiso profundizar sobre el tema: llegó primero al Colectivo de Abogados José Alvear Restrepo y luego a los familiares de los desaparecidos, que también participaron dentro de la investigación.

Finalizada la etapa anterior, iniciamos el proceso analítico de la información; se hizo la transcripción textual de las entrevistas, para luego organizarlas, teniendo en cuenta que los testimonios aparecían de manera caótica, de acuerdo con las formas en que las personas organizan sus recuerdos, de manera no lineal; por el contrario, los recuerdos van emergiendo desordenadamente en la medida en que se activan con el avance de la entrevista, por tanto, en el momento de llevarlos al papel era necesario organizarlos, y al mismo tiempo ir editando el testimonio para darle forma de crónica escrita. Luego, se jerarquizó y ordenó la información de acuerdo con los temas y categorías que iban apareciendo de manera inductiva en el desarrollo de la entrevista, para darle consistencia interna y una edición que permitiera al lector hallar un texto fluido y coherente.

Al final, producto de la investigación, resultó un voluminoso documento con todas las crónicas elaboradas a partir de los testimonios de los distintos grupos sociales, que permitió reconstruir los acontecimientos sobre el Palacio de Justicia, a través de la memoria de los que participaron directa e indirectamente de los hechos. Además de los análisis de las representaciones simbólicas que existen en la actualidad sobre el acontecimiento y que guían los imaginarios colectivos sobre la violencia actual y el movimiento guerrillero M-19.

\section{Crónica de un soldado entre las llamas ${ }^{4}$}

\section{Del colegio al ejército:}

\section{unas vacaciones con uniforme y fusil}

Desde tercero de bachillerato estudié en el Juan Ramón Jiménez, pero finalmente me gradué del Colegio Británico. En el sorteo que hacían en el colegio, salí eximido, pero

4 Esta crónica fue elaborada a partir del relato de David Mauricio Sánchez por Jessica Villamil, estudiante del Liceo Juan Ramón Jiménez.
El documento final ha sido socializado en eventos académicos de carácter nacional e internacional y ha sido analizado por los estudiantes de la licenciatura en Educación Básica con énfasis en Ciencias Sociales, de la Universidad Pedagógica Nacional, quienes se interesan por la situación de la memoria colectiva sobre el hecho y el desarrollo metodológico, que se convierte en una fuerte herramienta didáctica para la enseñanza de la historia y de las ciencias sociales. El documento final no pudo publicarse en el colegio donde se realizó la investigación, por los temores que despertaron en las directivas las afirmaciones del presidente actual de Colombia, quien relacionó el hecho con el narcotráfico para destruir los archivos e impedir cualquier proceso judicial que los involucrara. El colegio decidió dejar archivadas las crónicas por las afirmaciones que allí se encontraban. Este artículo se convierte en el esfuerzo final por socializar parte de la experiencia investigativa y los resultados de la misma, desde una perspectiva que aporte a la didáctica de la historia y a la enseñanza de las ciencias sociales, aunque las heridas de la violencia continúen hoy abiertas.

\section{Resultados de la investigación}

Para todos los que participamos en el proyecto, el resultado final se encuentra en las crónicas elaboradas al final de la investigación; por eso presentamos a continuación una síntesis de una de las crónicas realizada por la estudiante Jessica Villamil; al final mencionamos las conclusiones generales de la investigación en el campo pedagógico y didáctico. Las conclusiones sobre el tema de la memoria colectiva y los hechos del Palacio de Justicia harán parte de otro documento.

mi diploma se retrasó entonces tuve que presentarme de nuevo, y esta vez sí me tocó ir al ejército con 19 años recién cumplidos.

La ida fue sencilla: en el Batallón Miguel Antonio Caro nos pusieron en un potrero inmenso a una cantidad enorme de estudiantes recién egresados de todas partes. Ese día el Guardia Presidencial llevó la banda de guerra, que dio una vuelta exhibiéndose. Entonces yo dije: "pues si me va a tocar 
prestar servicio mejor que sea en la banda de guerra y no en la policía militar o en batallones aburridores".

Como tenía algunas nociones de música, ingresé a la Banda de Guerra del Batallón Guardia Presidencial, ubicado en la Plaza de los Mártires. Mi contingente fue el primero del año 85 , que comenzaba el 1 de enero y terminaba el 31 de diciembre, es decir, que para mediados de noviembre estábamos a punto de salir, y en ese momento la visión era de estar con un pie por fuera, con una actitud disipada, relajada, ya eran 11 meses de estar en el ejército.

La ceremonia diaria de la banda de guerra era el cambio de guardia, que se hacía subiendo por la calle décima, dando una vueltica por la Plaza de Bolívar y finalmente entrando por la séptima a la Casa de Nariño, donde se hacían relevos con los centinelas que se habían quedado el día anterior. Después salíamos dando otra vuelta por la Plaza de Bolívar y bajamos por la calle 11, por San Victorino hasta la Caracas. Era un paseíto chévere todos los días a las cinco de la tarde.

Además del cambio de guardia, era largo el tiempo que permanecíamos fuera del batallón, pues salíamos también a colegios, batallones y paradas militares. Además, nos trepábamos en montonera en los camiones militares con un morralito y un fusil, a hacer requisas por el centro en la noche.

El servicio militar en esa época no fue de combate ni orden público, era como un paseo, unas vacaciones raras con uniforme y fusil. Al principio estaba muy angustiado, pero al cabo de dos semanas me di cuenta que estaba con un poco de muchachos en las mismas condiciones, todos despistados, y ya aterrizando con que definitivamente nos tocó quedarnos prestando servicio militar acá. De lo que uno se da cuenta es que no se va a morir, y que por estar entre un combo de muchachos de la misma edad pasan cosas divertidas.

En el Ejército conocí cosas especiales como la milicia, que significa mil personas iguales y uniformes, es decir, que todos se vean igual y piensen igual, logrando una homogeneidad que permite que haya una cohesión de grupo y con esto la conformación de un cuerpo. Por eso es que los soldados son jóvenes, porque es fácil moldear el pensamiento, pues lo que hay es un trabajo sicológico, es un arte porque se logra manejar la gente y hacer que las cosas se muevan con orden.

Esto fue complicado, pues yo venía de un colegio de alguna manera reaccionario, con amigos de izquierda, con papás que alguna vez se rozaron con el M., con una visión muy diferente, y de pronto ipum!, uno da el salto al lado opuesto. De todas maneras uno se crea muchos mitos sobre el ejército, y la verdad yo me sorprendí porque encontré mucha gente buena y caballerosa; aunque soy consciente que también hay gente atravesadísima y anticomunista como el general Millán, que era un tipo muy duro, un típico reaccionario que no se le podía mencionar nada sobre comunismo.

\section{Incertidumbre y realidad}

En la banda de guerra cambiamos los fusiles por instrumentos, el uniforme militar por un vestido de paño, y solo esporádicamente limpiábamos nuestro armamento, ya que lo usábamos con poca frecuencia. Sin embargo un día de noviembre estábamos en una revisión de armamento cuando de repente sonaron tres alarmas; y no era un simulacro. Pero el teniente, un poco torpe, se fue hasta la oficina del Comandante del Batallón a pedir información, a certificar qué pasaba, pero se caía de su propio peso que lo que había que hacer era coger el armamento, empacar las balas en las cartoneras y ponerse todo el equipo.

$\mathrm{Al}$ dar la orden de salida, nos "avalanchamos" todos hacia la puerta del batallón y salimos corriendo a la loca. Cruzamos corriendo la Caracas, y subimos al trote por la décima hasta la octava, cerca de la Plaza de Bolívar, donde ya se alcanzaban a oír disparos. Ya estando frente a la Plaza lo más impactante fue la inmensa soledad, ya debían haber pasado unos diez o quince minutos desde que se iniciaron las acciones. El ambiente comenzaba a sentirse extraño, pues todo se veía muy gris y frío, eso fue como a las dos de la tarde y creo que no habíamos almorzado.

Lo vivimos todo, fue algo que nadie nos contó, o alguien vino a decirte o a confirmarte, simplemente las cosas pasaban.

Había muchos disparos, y cuando llegamos no había más que ejército, entonces algunos compañeros entraron por el parqueadero del edificio que quedaba por la carrera octava; y otros nos fuimos hacia el área del Palacio de Nariño. Eso fue como de película, de García Márquez, porque en ese momento en el Observatorio Astronómico había una presentación de credenciales y una banda de guerra, también del Guardia Presidencial pero de músicos profesionales, tocaban los himnos de los países y no paraban, aun cuando en el otro lado habían disparos desde quince minutos antes.

Sí, en el Palacio de Justicia había una balacera tremenda, ocurría una cosa gravísima, se estaban tomando la Corte Suprema de Justicia. 


\section{Un asunto folclórico y desordenado}

A pocas horas de haberse iniciado el combate, hubo un incendio en esa zona donde decían que había archivos del narcotráfico, pues recuerdo haber visto salir humo en esas áreas del sótano. Pero igual no se sabe lo que realmente pasó, si los quemaron con alguna intención. La verdad es lo más manipulado que hay, yo que estuve ahí no tengo ni idea de lo que pasó realmente.

Pasó un tiempo y empezaron a llegar camiones con ejército, gente de la Escuela de Logística, de la Escuela Militar, los tanques cascabel de la Escuela de Artillería, del Cantón Norte, de la Escuela de Infantería. Había mucha policía, mucho ejército, mucho celador, mucho tira, mucho DAS, ¡muchísimo!

Recuerdo a civiles que llegaban con cajas completas de municiones, y nos repartían a todos así a la lata y decían “iqué necesita? ¿granadas?, ¿balas?, ¿qué necesita?”. Un asunto bastante folclórico, la munición no se pedía en una ventanilla, sino que la iban regalando en mitad del combate.

Me acuerdo del coronel Plazas, de la Escuela de Artillería, caminando por la Plaza de Bolívar, mientras le disparaban pegándole los tiros en el suelo. Él fue quien ordenó que los tanques subieran, y se tiraron los andenes de piedra y las gradas de la Plaza de Bolívar, aunque eso al ejército no le importaba. Al treparse en la plataforma el tanque se encaminó directamente a una puerta de vidrio del Palacio de Justicia, que estaba cerrada, y comenzó a ametrallarla, aunque solamente la perforaba. Había muchos vidrios rotos, y como esos vidrios tienen seguridad, el tanque comenzó a avanzar y a hacer tanta fuerza que desplomó la inmensa puerta.

Fue una imagen bonita, como de cine, pues es diferente cuando está en la pantalla de un televisor, pero cuando lo ves en vivo y en directo, con el ruido y todo lo que está pasando son cosas visualmente atractivas. Además, nosotros disfrazados de soldados, armados, en un desorden terrible, sentíamos el impacto de las acciones y escuchábamos los combates, los helicópteros en la azotea; y bueno... dos horas después de haberse iniciado la toma eso ya estaba decidido.

El desorden se debía también a la desconexión con los mandos, pues íbamos 70 soldados con tres mandos, y resultamos solo con uno. Y aunque hubo órdenes, las cosas se hacían por iniciativa de cada persona, pues en los dos días que duró la toma, entraba y salía mucha gente, haciendo lo que les parecía.
Yo únicamente digo es que cuando se juntan armas, cuerpos militares y gente, eso tiene una dinámica propia, pues las decisiones no las toma una persona, no hay un eje que mueva las cosas. Se puede parar la gente, pero no se puede determinar qué va a hacer cada persona, entonces lo que el ejército creó fue una maquina que los arrolló, pues las acciones no dependían de los generales, eso lo sé yo que estuve allá durante dos días.

\section{La muerte se vive y el terror se percibe}

Estando en el Palacio lo único que yo tenía que hacer era ayudar a sacar gente; todo el mundo muy degradado, angustiado, la gente temblaba. Además tenía también que disparar; en un corredor había un teniente loco que estaba tratando de avanzar y le estábamos abriendo campo: al estilo rambo, se asomaba y gritaba "hombre guerra", y nosotros disparábamos unas ráfagas tremendas y él se cruzaba de una pared a otra avanzando de a poquitos.

En algunos momentos se escucharon unos disparos en un callejón, pero nunca se supo si se estaba disparando a los amigos o a los enemigos, porque eso se mueve así, cuando no hay una dirección muy clara, la confusión es tremenda, y yo creo que hubo muchos muertos por disparos cruzados. Recorriendo el edificio había que disparar y esconderse porque la onda explosiva era muy fuerte, y se siente intensamente en el cuerpo, las personas se ven como fantasmas, una imagen extraña, consecuencia de la expansión de la explosión, además del ruido y esas cosas.

Dentro del Palacio de Justicia definitivamente estábamos en libertad y sin mando, los ingenieros con los artilleros, con los de caballería, todos en recocha. El asunto era tremendo, disparos, granadas, guerra, era como jugando, como en cine, pero en serio.

Tristemente desde ese momento ya se veía que eso iba a ser una hecatombe, ya olía muy mal, el terror y la muerte se huelen y se perciben, uno ve que el terror existe, el terror se transmite y se percibe, tiene un aura, todas esa cosas pasan ahí, y uno siente la presencia del terror en lo que está pasando. Lo peor es que el hombre tiene la capacidad de ser absolutamente indiferente al terror: uno siente que esta ahí, que lo pueden matar, que uno puede matar, pero que es todo muy fácil. No hay muchas barreras morales ni éticas, ni cuestionamientos que sean difíciles de sobrepasar en ese momento, el cuerpo se pone a la altura de lo que esté pasando, y simplemente se desenvuelve.

El olor de la pólvora era un ambiente especial, como en un aeropuerto donde uno siente el olorcito a la gasolina de 
avión, y el aeropuerto huele a aeropuerto, pues ese sitio olía a pólvora, en una sola palabra, a muerte.

\section{Recorrido en las ruinas en blanco y negro}

Ese día estuve ahí hasta las siete de la noche, y me fui, porque no habíamos almorzado, y estábamos muy agotados por el olor a pólvora. En la noche hubo un incendio que yo nunca viví, lo vi en televisión. Y al día siguiente fui de nuevo al Palacio, porque estaban llegando al alojamiento de nosotros compañeros totalmente negros por el humo, estaban absolutamente tiznados. Mientras ellos se reponían, los que ya habíamos descansado nos dirigíamos al Palacio.

Desde el primer día se veía que la cosa estaba perdida. Sin embargo, la toma duró bastante tiempo, dos días, pues hubo resistencia, presión, rehenes, intento de negociación. Además, había muchísimos civiles allá adentro, de ese edificio salió muchísima gente porque los muertos que hubo fueron como ochenta, y si hubo ochenta muertos había 500 o 600 personas en el edificio.

En la tarde del segundo día, en el Palacio ya la cosa estaba definida, ya había ocurrido el incendio que fue tremendo. Dimos un paseo por el edificio, lo único que quedaba eran unos soportes verticales y los vidrios estaban totalmente reventados. El suelo estaba cubierto por una capa de cenizas de 15 o $20 \mathrm{~cm}$, que estaba hirviendo, y con esas botas tenía que estarme moviendo todo el tiempo porque si no se me quemaban los pies. Ese día recorrer el edificio, recorrer las ruinas, mirar el estado de todo, vagar por ahí, uno entra en una desconexión, queda en automático.

Caminando por ahí comenzaba a ver grupos de gente que había muerto durante el incendio. De repente, viendo las cenizas un amigo dice "¿eso ahí redondo qué es?... es un cráneo", "uy sí, es un cráneo", "¿y eso de allá qué?... un brazo" “iy eso? como un.... Los cuerpos al quemarse se mutilaron y se desperdigaron, quedaba el hueso de la rodilla, el cráneo, partes de las costillas, y el corazón que es un órgano superfuerte, casi todo el mundo tenía el corazón, achicharrado, pero lo tenían.

Además de muertos encontramos mucho armamento por ahí tirado. Después bajamos por una escalera, estaban los últimos guerrilleros que habían muerto, y todo en blanco y negro por el incendio. Quedaron ahí tirados en tres pisos de escaleras, se veían muy bien, a pesar de estar quemados, ensangrentados, despeinados y lo que fuera, se veían muy bien, muy decorosos.

Finalmente llegamos a la plazoleta central del edificio, adonde llevaban los muertos y directamente los bomberos les ro- ciaban las caras para comenzar a identificarlos. Me acuerdo mucho de un guerrillero famoso, un viejito intelectual de la guerrilla que estaba ahí presente, que dirigía esa toma: Almarales, a él le dieron un tiro en el ojo que le hundió toda la cuenca. Para la identificación había gente de inteligencia del Ejército que tenían unos álbumes completísimos de cada guerrillero, con fotos tomadas en unas conversaciones que hubo con Pizarro en Santo Domingo (Cauca).

\section{Una máquina incontrolable de desafuero y locura}

Durante la acción militar en el Palacio de Justicia, lo que se creó fue una máquina muy difícil de detener, porque, aunque mi visión es ecuánime comparada con el resto de los soldados, era evidente que había gente que quería ir a disparar, a ver qué hacía, a quién mataba, qué explotaba. Cuando se desencadena una fuerza de esas, no es tan fácil frenarla, pues hay soldados que quieren ir a estrenar sus fusiles, hay tenientes que quieren ganarse la medalla, hay coroneles que quieren ser promovidos, hay gente que quiere hacer méritos.

Tampoco había una acción clara de ponerle frenos al ejército, y la decisión era que definitivamente la toma continuaría hasta que muriera el último guerrillero. Además, porque el ejército fue claro en asumir las acciones sin tener en cuenta la intervención del presidente.

Eso se sintió claramente, pues en esos dos días el presidente no gobernaba, yo lo que pensaba era: "3:00 p. m., hora cero de la toma. Comenzó la toma, hora y media después de la toma, va a haber un golpe de Estado. Increíble, se va a ver lo que nunca se ha visto". Y además contradictorio, porque la primera lealtad de los soldados del Guardia es con el Presidente, ni siquiera con el ejército y la milicia. Y pues era extraño porque era a nosotros a los que nos iba a tocar darle el golpe al Presidente; y además Belisario, que era el poeta, el bonachón, el que hablaba de paz, era como otro rollo, no era completamente de derecha.

El Presidente podía pararse y gritar, hablar en televisión o donde quisiera, pero lo que él dijera a una cuadra, o así se viniera hasta el lugar del hecho, a la gente le iba a resbalar, a todo el mundo, a la tropa, a los tenientes, a los coroneles, porque lo que estaba pasando era mucho más grave que lo que él pudiera decir.

Para nosotros, como Ejército, lo único que pasó ahí fue que las vacaciones obligadas de un año con uniforme estaban terminando, y hubo una acción de combate que nos despertó de la modorra del batallón, nos sacó de ahí y nos puso en aire de combate. Hubo mucho desafuero y mucha locura en esta 
toma; fuera del impacto cinematográfico y emocional que tiene eso, fue un acontecimiento muy triste: se derrumbó un edificio y acabó con toda la gente que estaba ahí. Lo peor es que no sirvió para nada, porque fue algo muy poderoso que comenzó mal y terminó peor.

\section{De una exitosa historia a una fracasada toma}

Yo tuve un amigo que estudiaba ciencia política en los Andes, se llamaba Alejandro [nombre cambiado] y fue guerrillero: guerrillero de monte, guerrillero urbano, guerrillero ideólogo, una persona muy inteligente, y muy preparada; que en el M-19, se llamaba comandante David. Nos decía que tenían una sede en La Candelaria, y habían acordado ir a la toma; pero el cuento es que el camión pasó más temprano y no pudo recogerlos a todos. El grupo que se había quedado bajó corriendo, pero cuando iban llegando por un costado de la Catedral se dieron cuenta que ya había empezado el combate, que estaba llegando policía y ejército.

El M-19 la embarró porque uno no puede hacer una cosa de esas sin asegurarse que va a poder controlar la situación. Siempre pensé que fue una acción loca del movimiento guerrillero en un momento en que estaban muy diezmados, y además porque todo estaba perdido en el momento en que no pudieron entrar todos; además, debieron haber puesto cargas explosivas para impedir la entrada de tanques, y haber bloqueado las entradas apropiadamente.

Acciones anteriores podían haberles hecho pensar que iban a tener éxito. El M-19 había pasado por la Embajada de República Dominicana, y era el que protagonizaba ese tipo de acciones espectaculares. Allí estuvieron metidos como tres o cuatro meses, un tiempo bien largo. De allí salieron victoriosos, con los brazos arriba, en el avión de Cubana de Aviación, y con dinero, creo que les dieron 2 o 3 millones de dólares a cambio de todos los embajadores que tenían de rehenes. Fue una toma victoriosa.

El Ejército no estaba dispuesto a repetir la humillación de tener que cercar a los guerrilleros, que al final mandaban la parada, pues eran los que decidían cuándo se sentaban a conversar, de qué hablaban, de qué no, con quién hablaban, con quién no. Entonces esta no era la misma oportunidad, la vez pasada porque había embajadores extranjeros, y todos esos países no permitieron que hubiera una masacre allí dentro, pero ahora el ejército no estaba dispuesto a humillarse y tenía la posibilidad de acabar con el movimiento guerrillero.

\section{Ejército en acto y potencia}

El ejército sabía que allá estaba parte de la cúpula del M-19, y había que aprovechar para matarlos, acabar con el enemigo: eso era una cosa muy clara. Hay mucha gente que dice que el ejército sabía que eso iba a suceder, que aprovecharon, y dejaron entrar a la guerrilla, para eliminarlos, y de paso acabar con todos los magistrados que son comunistas. La verdad yo no creo que el ejército haya sabido, porque si la idea era hacerles una encerrona, los transportes habrían llegado mucho mas rápido, y el orden y el desarrollo al puro principio habrían sido muy distintos.

Con el ejército, la milicia y el uniforme, la parte política se refleja simplemente en el común de la tropa, y en ese momento el contenido político del asunto no incidió en la acción que teníamos que ejercer, pues en el ejército eso está muy controlado, no hay participación política y cuando hay manifestaciones son de derecha. Los soldados estamos ajenos a todo eso, porque uno es un cuerpo con el resto de los muchachos y las discusiones políticas nunca se daban.

Pero también me di cuenta que en el ejército, a pesar de estar en la derecha, uno puede ayudar, después de prestar servicio militar me di cuenta que sí habría algo que le pudiera ayudar muchísimo al país sería el ejército, aunque en otras condiciones, pues la capacidad de movilización y ejecución es muy grande. Si el ejército estuviera en otro panorama, esto podría ser un instrumento muy positivo para el desarrollo del país, porque no necesariamente tiene que ser en combate o armados, pero la idea filosófica que reúne a los soldados a permanecer unidos, a estar durmiendo juntos, comiendo juntos, con el fusil, a hacer acciones conjuntas, eso podría ser un potencial tremendo.

\section{Sentido común}

El M-19 ha sido un grupo que políticamente no sé si tiene razón o no tiene razón, porque la política es una cosa tan sencilla que es de puro sentido común. No puedo decir que son malos porque son de izquierda, ellos tienen razón en ciertas cosas; y los que son de derecha también tienen razón en ciertas cosas, definitivamente es puro sentido común.

La verdad es que no comparto la forma de hacer las cosas de una guerrilla, es un miedo personal, la clandestinidad, porque yo soy una persona con los pies sobre la tierra, que debe tener cierta seguridad en las acciones, y me parece que en la clandestinidad hay una forma de vida del día a día que no me parece bonita. 
Igualmente creo que hay mucha gente que está detrás de una acción noble, una acción ética y moralmente positiva. Es el caso del $\mathrm{M}$, pues de alguna manera era respetable y honorable combatir con el M-19, había un acto de respeto con ellos, no sería lo mismo combatir ahora contra la guerrilla o los paras, porque en ellos claramente uno siente que hay algo torcido. Ahora la situación de honorable no tiene nada, la violencia cada vez es peor, y ya no existen los límites, pues hace mucho tiempo el combate tenía cierta ética, que cada vez se ha ido degradando más, porque solo se buscan todas las argucias posibles para vencer.

Realmente lo que intentaban con la toma del Palacio de Justicia era hacer un juicio al Presidente, y poner a los

\section{Conclusiones}

La investigación "La toma del Palacio de Justicia en la memoria colectiva" finalizó en el año 2005, como documento conmemorativo de los 20 años de la toma y retoma del Palacio y memoria escolar de los que allí cayeron o se encuentran desaparecidos. Las conclusiones que presentamos a continuación hacen parte del componente pedagógico y didáctico que surgió a partir del trabajo que se realizó desde la historia oral, quedan por fuera las conclusiones derivadas de la investigación en sí misma. A continuación están los avances significativos y las dificultades halladas durante el proceso:

- Los estudiantes comprendieron la importancia de la historia del tiempo presente que supera la visión de un pasado, que antes se quedaba en la época de la Violencia partidista de los años cincuenta. A partir de la investigación pudieron reconstruir, ellos mismos, un hecho histórico del cual tenían pocas referencias a pesar de la cercanía cronológica.

- La investigación permite establecer una relación intergeneracional en la que valores, visiones del mundo, posturas políticas, etc., fueron reconocidas durante la aplicación de las entrevistas.

\section{Referencias}

CANDAU, Joel. 2002. Antropología de la memoria. Buenos Aires: Nueva Visión.

CASTRO, Fabio. 2004. Historia oral: historias de vida e historias barriales. Bogotá: IED Manuelita Sáenz, Colectivo de Historia Oral, Aspectos Siglo XXI. magistrados, los jueces, hacer un proceso revolucionario espectacular. Hacer una toma larga, que se convertiría en un paso para la carrera política del M-19, si no hubiera tenido tantas fallas, pero un edificio de esos en el centro de Bogotá es muy difícil de sostener, así uno tenga 40 personas combatientes; es tan difícil, $\tan$ loco lo que ellos intentaban.

El M-19 tenía una cosa positiva y es que era una guerrilla que combatía, con líderes que combatían, no como las FARC que es una guerrilla de aristócratas que mandan un poco de chinos a que combatan, que ni siquiera combaten sino que usan el terrorismo. Pero no hacen lo que hacía el M-19, que era irse con unas armas infelices, de pequeño calibre a hacer cosas que ponían a pensar al país.

- Incorpora elementos metodológicos de la investigación cualitativa que, en circunstancias regulares, difícilmente hubieran podido adquirir.

- Los estudiantes tienen la posibilidad de producir conocimiento y recurren a fuentes que les son cercanas.

- Por ser un tema de la violencia reciente de Colombia, aún quedan heridas abiertas difíciles de cerrar y existen temores por parte de la comunidad escolar por tocar este tipo de temas.

- Como es una innovación didáctica, inicialmente surgen dificultades en el momento de aplicar las entrevistas, hasta que el entrenamiento permite un mejor desenvolvimiento.

- Permite que los estudiantes desarrollen adecuadamente competencias lingüísticas desde el momento de diseñar las propuestas, estructurar las entrevistas y la redacción de las crónicas finales.

- Facilita el trabajo en grupo y reconocer que el conocimiento es una producción dinámica y colectiva.

- Permite guiar a los estudiantes por los caminos de la investigación que supera la visión estática de las personas frente al conocimiento.

ORTIZ, Carlos Miguel. 1995. "Historiografía de la violencia". La historia al final del milenio, vol. 1. Bogotá: Universidad Nacional de Colombia.

RESTREPO, Laura. 1986. Historia de una traición. Bogotá: Plaza y Janés. 
SITTON, Thad y MEHAFFY, George. 1989. Historia oral: una guía para profesores (y otras personas). México: Fondo de Cultura Económica.

TORRES, Alfonso. 1993. Iniciación a la investigación histórica. Bogotá: Ediciones Universidad Santo Tomás.

VEGA, Renán. 1999. Historia: conocimiento y enseñanza. Bogotá. Ediciones Antropos.

\section{Diálogo del conocimiento}

"Cuando el dinosaurio despertó, todavía estaba alli". Este corto pero ingenioso cuento de Augusto Monterroso ilustra de manera inteligente el significado de la vida, su finitud y su inmanente lugar en la memoria. El dinosaurio no solo despertó y estaba vivo, sino que todavía estaba allí, es decir que todavía tenía conciencia de su existencia, su vida aún albergaba sentido, gracias al poder de la memoria, seguía siendo él mismo su protagonista. Es el tiempo que no pasa, la vida o los hechos de la vida que no permitimos que fenezcan o se queden en el sopor del sueño, se releguen sin indulgencia en el olvido.

En esta dirección se sitúa el trabajo de investigación realizado por un grupo de estudiantes del colegio Juan Ramón Jiménez: "La toma del Palacio de Justicia en la memoria colectiva", como recreación de un suceso tan trascendente como doloroso en la historia de Colombia; uno de esos instantes que se quedan recogidos en el álbum fotográfico de los hechos o las tradiciones, pero que tienden al desgaire a relegarse y a quedar como imagen o letra muerta en los anaqueles de las bibliotecas, en el mejor de los casos, o de cuando en cuando paseándose entre las manos cansadas de los archivistas.

Por eso la validez de este documento que, haciendo uso del significado y el valor de la memoria colectiva, intenta reconstruir los hechos de la toma del Palacio de Justicia el 6 y 7 de noviembre de 1985, poniéndolos en boca de algunos de quienes fueron directamente sus protagonistas. Un soldado del batallón guardia presidencial, un grupo de mujeres que fueron militantes y una líder del movimiento que protagonizó los hechos, el M-19, así como algunos testigos presenciales, comparten desde sus propias narraciones lo que fueron las vivencias de ese instante, para ellos todavía presente, de casi 24 horas de haber visto el símbolo máximo de la justicia colombiana envuelto en llamas.

El trabajo es también una muestra ejemplar de lo que significa la enseñanza de la historia más allá de los confines del aula y la manera de involucrar al estudiante como un productor mismo de saber y conocimiento; una forma de hacer de este un protagonista más de hechos que acaso no vivió, pero que no por ello dejan de ser parte de su acontecer y de su vida; pues, como aquí se hace evidente, en la dimensión del tiempo y su correlato en la memoria, los hechos involucran a los personajes y CASTAÑO, Ricardo (compiladores). 1999. Déjenos hablar. Bogotá: Universidad Pedagógica Nacional - Instituto de Investigación Educativa y Desarrollo Pedagógico.

VÉLEZ, Humberto y ATEHORTÚA, Adolfo. 1993. Militares, guerreros y autoridad civil: el caso del Palacio de Justicia. Cali: Universidad del Valle-Pontificia Universidad Javeriana.

VILAR, Pierre. 1999. Iniciación al vocabulario del análisis histórico. $6^{a}$ edición. Barcelona: Crítica.

del pasado, los del presente y advierten así mismo el acontecer para las generaciones futuras. No es gratuito que uno de los protagonistas de la investigación era tan solo un niño cuando los hechos sucedieron y que, gracias a este trabajo, se convierta hoy precisamente en uno de los personajes que viven ese momento como escucha e intérprete de su recuperación a través de la memoria histórica.

Recurrir a la historia oral como parte del acervo metodológico manifiesta de hecho una comprensión diferente del quehacer pedagógico y del papel que en él le corresponde al docente. La experiencia recogida en este artículo es entonces un aporte en doble vía; por un lado para quienes creen que no es posible ni lícito que hechos de tanta trascendencia e importancia para la historia de la nación se lleven al rincón del olvido y, por otro, porque es un valioso aporte para la labor del docente y para la pedagogía misma.

La participación activa de los estudiantes, se afirma en la descripción metodológica que orientó la investigación, es, a más de una manera de aprender historia haciendo historia, la validación de un procedimiento de investigación en el que con la recuperación de la tradición oral se da voz a los tradicionalmente excluidos; es decir, que es también una apuesta por la democratización del saber o, si se permite la expresión, por la democratización de los procesos de socialización del conocimiento y de la manera como se cuenta la historia, siempre ligada a los cómodos narradores oficiales que dejan poco a quienes son o han sido su verdaderos protagonistas.

Finalmente, es importante resaltar la modestia y humildad -que para nada desdice del rigor y seriedad académica-, de este tipo de propuestas de investigación; pues no pretenden asumirse como la verdad revelada, sino que, por el contrario, reclaman así mismo la vaguedad y fragilidad de la mente humana frente a los hechos y al conocimiento; es decir, que esta no se pretende como la historia oficial, pero tampoco quiere asumirse como la verdad de la historia. Es la narración vivencial, el sentido y las emociones descritas por parte de algunos de sus protagonistas, a los que por tanto habrá que creer, como a cada uno de los que así mismo se atrevan con sus propias narraciones. Pues habrá tantas verdades como historias contadas, aun para un mismo hecho. Esa quizás es su principal enseñanza. 